\title{
ASSESSMENT OF PORCELAIN FUSED TO METAL BOND STRENGTH AFTER LASER SURFACE TREATMENT OF RECYCLED COBALT-CHROMIUM ALLOY
}

\author{
Mohammed Suleiman Alruthea*
}

\begin{abstract}
Recycling of casted alloys in dentistry is sometimes done to reduce price and minimizing environmental hazards. The current study assessed the use of laser surface treatment to enhance the shear bond strength between porcelain and Cobalt-Chromium alloy hindered by adding ratios of recasted alloy. Ninety disc-shaped samples were fabricated and assembled into six groups. Group A fabricated from fresh alloy without laser treatment (negative control), group B fresh alloy with surface treatment by laser (positive control), group C-75\% fresh alloy mixed with $25 \%$ of once recasted alloy followed by laser treatment, group D-50\% fresh alloy mixed with $50 \%$ of once recasted alloy followed by laser treatment, group E- $75 \%$ fresh alloy mixed with $25 \%$ of twice recasted alloy and laser treated and group F-50\% fresh alloy mixed with $50 \%$ of twice recasted alloy and laser treated. The results revealed non-significant values were calculated between group A (negative control group) and groups B, C, D, E and F with significance values $(0.059,0.612,1.000$, 0.922 and 0.845$)$. Similarly, the difference between groups C, D, E and F showed non-significant values $(0.479,0.117$ and 0.074$)$. A significant difference at 0.05 level was seen between group $B$ (positive control group) and group D, E and F with significance values $(0.037,0.003$ and 0.002$)$ respectively. Accordingly, laser surface treatment might be used as an effective surface treatment after adding recycled alloys to casting process in order to enhance bond strength with ceramic materials.
\end{abstract}

\section{INTRODUCTION}

There has been a concern regarding the reuse of casted alloys in dentistry. This concept has even extended to include recycling of dental zirconia waste resulting from CAD CAM manufacturing process ${ }^{(1)}$. Recycling of dental alloys has been applied in many dental labs to reduce cost and minimize environmental hazards of materials used. However, alloys recycling procedure should be used with caution to avoid the detrimental effects expected from recasting process. The quality of the casted part may affect the efficiency of the interface between casted products and the outer esthetic

* Assistant Professor, Prosthodontic Department, Dental College in Alrass, Qassim University, Kingdom of Saudi Arabia.. 
layered materials like porcelain. There is a debate about the reusing of recycled dental alloys in dental laboratories ${ }^{(2-7)}$.

The ratio of the allowed amount of recasted alloys was studied in several researches ${ }^{(8-13)}$. According to Anusavice ${ }^{(7)}$, the average value of the allowed amount of the recasted alloy was $50 \%$ by weight. However, there was no consensus about the maximal amount that should not be exceeded when mixed with the fresh alloy ${ }^{(3)}$. The recommended maximum ratio varied from $100 \%$ of recasted alloy permitted ${ }^{(12)}, 75 \%$ of the recasted alloy amount ${ }^{(9)}$, $50 \%$ recasted alloy ${ }^{(3,8,11,13)}$ to less than $50 \%$ of the recasted alloy ${ }^{(10)}$. In addition, another parameter studied was the number of recycling performed and how could it affect the quality of the castings and their bond strength to ceramic materials ${ }^{(3)}$.

This recycling process of the alloys was not only affecting corrosion, yield strength, surface hardness, and flexural strength but also can change the element distribution within the alloy $(8,13,14)$. Other studies highlighted the effect of the recasting on the mechanical properties by changing the macrostructure and the incorporation of minute porosity in the core of the recasted alloys as seen by the scanning electron microscope (SEM) ${ }^{(6,12)}$. Another very important property influenced by the alloy recasting is the bond strength between alloys and the porcelain surfaces of porcelain fused to metal restoration ${ }^{(8,9)}$. This reduction in the bond strength was directly associated with the elemental surface change that happened due to the recasting process. The researchers reported reduction of concentration of some elements at the metalceramic interface. Importantly, the concentration of cerium was extremely decreased in the intermediate phase, followed by niobium, molybdenum, nickel and chromium concentrations as well as the incorporation of some impurities during recasting and the thickness of the interface between castings and porcelain $^{(14,15)}$.
Many researches were conducted to enhance bond strength between casted alloys and ceramic materials ${ }^{(15-20)}$. Some trials focused on surface treatment of the recycled alloys to remove surface impurities contamination and improve surface energy by airborne-particle abrasion and itching with different chemical solutions with different timing protocols to remove the surface of the recycled alloys ${ }^{(16)}$. There was recommendation to use air-abrasion with alumina at high pressure, polishing with abrasive rubber wheels and cooling with distilled water to provide strong luster and good clinical quality ${ }^{(17,18)}$. Another suggestion was to apply airborne-particle abrasion of recasted alloys using alumina particles then chemically treat them with a mixture of acids ${ }^{(4)}$. However, no standard specific protocol was successful for all to enhance their surface characteristics ${ }^{(15,16)}$.

There were some trials to enhance bond strength between base metal alloys and porcelain (21-24). One of the methods used to enhance alloy surface for bonding was thermo-mechanical cycling ${ }^{(22,23)}$. Another effective surface treatment was the laser surface treatment. Some researchers apply different laser treatment protocols to activate surface energy and enhance bonding at the interface between casted alloys and ceramics and even by laser etching for ceramic crown before cementation ${ }^{(21,24,25)}$. Laser showed better bond strength than air-abrasives and researchers appreciate its bond strength enhancement (24). Accordingly, researchers confirmed that laser surface treatment was a successful alternative to air-abrasion protocol in enhancement of the shear bond strength between alloy surface and porcelain material.

The use of shear bond strength to evaluate the metal-ceramic interface was considered and preferred than three-point loading test ${ }^{(21,26)}$. The maximum ratios and number of recasting alloys allowed without affecting the properties of the final casting were intensively studied. Furthermore, the beneficial use of laser surface treatment on the totally-fresh alloy surface was also evaluated. 
However, no article was conducted to improve the bond strength between porcelain and partially recycled alloys using laser surface treatment. Accordingly, the aim of the current study was to evaluate the influence of using laser as a surface treatment on the metal-ceramic shear bond strength of alloys prepared with different ratios and times of recasted to fresh casted alloys. The hypothesis of the current study was that laser surface treatment will enhance the shear bond strength at the metalceramic interface of the recycled alloys regardless of their ratio or number of recycling.

\section{MATERIALS AND METHODS}

\section{Samples preparation}

Ninety samples were fabricated from the CobaltChromium alloy, based dental metal-ceramic alloy Type 5 (Ivoclar Vivadent, Colado CC,Liechtenstein); whose chemical compositions were $\mathrm{Co}-\mathrm{Cr}$ (59.0\% \& $25.5 \%$ ), using induction casting machine as per manufacturer's instructions. The metal samples were in the form of cylinder of dimension $4 \times 4 \mathrm{~mm}$, with a base of 5x1mm was made, (fig. 1). Except for the negative control group, laser surface treatment was performed, followed by adding opaque and body porcelain to the metal surface to a thickness of $4 \mathrm{~mm}$ as per the manufacturer recommendation.

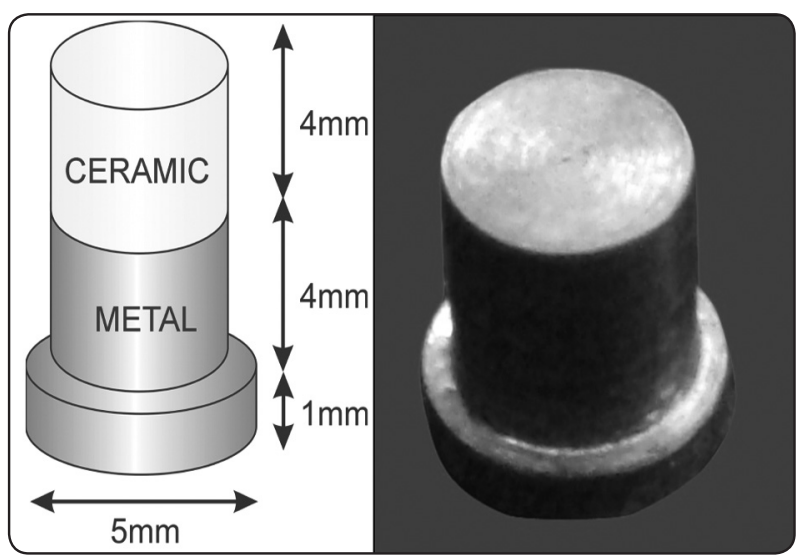

Fig. (1) Diagram showing sample dimensions, left. Metal part of the sample ready to receive the opaque and porcelain build-up.
A power analysis was performed using an online calculator (http://powerandsamplesize.com/ Calculators/Compare-k-Means) to detect the sample size of the patients. Ninety subjects were calculated to yield a power of $80.3 \% \mathrm{SD}=9.82$, alpha $=0.05$. The 90-porcelain fused to metal samples were divided into six groups according to the percentage of once recasted and twice recasted alloy used as follows:

- Group A - 100\% fresh alloy without laser treatment (negative control)

- Group B - 100\% fresh alloy treated by laser (positive control)

- Group C - 75\% fresh alloy mixed with $25 \%$ of once recasted alloy + (laser treatment).

- Group D - 50\% fresh alloy mixed with 50\% of once recasted alloy + (laser treatment).

- Group E-75\% fresh alloy mixed with $25 \%$ of twice recasted alloy + (laser treatment).

- Group F - 50\% fresh alloy mixed with 50\% of twice recasted alloy + (laser treatment).

A cylindrical die of dimensions $(4 \times 4) \mathrm{mm}$ with a base of $5 \mathrm{~mm}$ diameter and $1 \mathrm{~mm}$ in height was made in brass for making standardised wax pattern. To achieve the standardized wax pattern for metal cylindrical specimen a silicon mold was fabricated, (fig. 2).

\section{Casting procedure}

During first casting $35 \mathrm{gms}$ of pre-weighed fresh alloy was used named as Group A and B (100\% fresh alloy). During second casting $26.25 \mathrm{gms}$ of fresh and $8.75 \mathrm{gms}$ of once casted alloy was used named as Group C (75\% fresh alloy). During third casting $17.5 \mathrm{gms}$ of fresh and $17.5 \mathrm{gms}$ of once recasted alloy was used named as Group D (50\% fresh alloy) and similarly during fourth casting $26.25 \mathrm{gms}$ of fresh alloy and $8.75 \mathrm{gms}$ of twice reused was used and named as Group E. During fifth casting $17.5 \mathrm{mg}$ (50\% of fresh alloy) and $17.5 \mathrm{mg}$ (50\% of twice reused), Group F. 


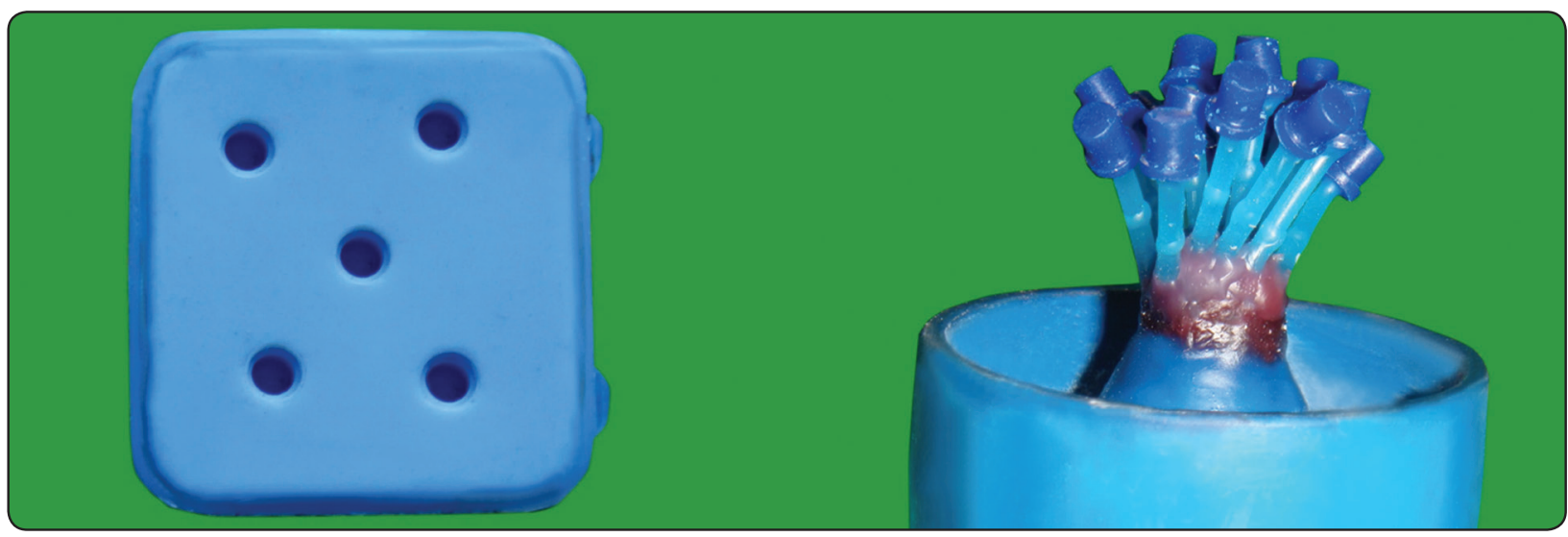

Fig. (2) Mold fabricated to standardize the sample wax pattern, left. Wax patterns of the samples sprued and added to investing ring.

Except for Group A, the finished samples of all other groups were treated by laser etching technique (21). Laser etching was done at the metal surfaces of the specimens by movement of a glass fibre of the Nd: YAG lasers (Neolaser L, Girrbach Dental Systems, Pforzheim, Germany) at a power setting of $2 \mathrm{~kW}$, representing energy and frequency levels of $120 \mathrm{mj}$ with $50 \mathrm{~Hz}$ frequency at a depth of 20 $\mu$ in $2 \mathrm{~mm}$ space interval then cleaned by ultrasonic cleaner to remove any impurities on the metal samples, (fig.3).

\section{Porcelain Build-up}

Before application of porcelain, all the samples were degassed and then the samples were ready for porcelain application.

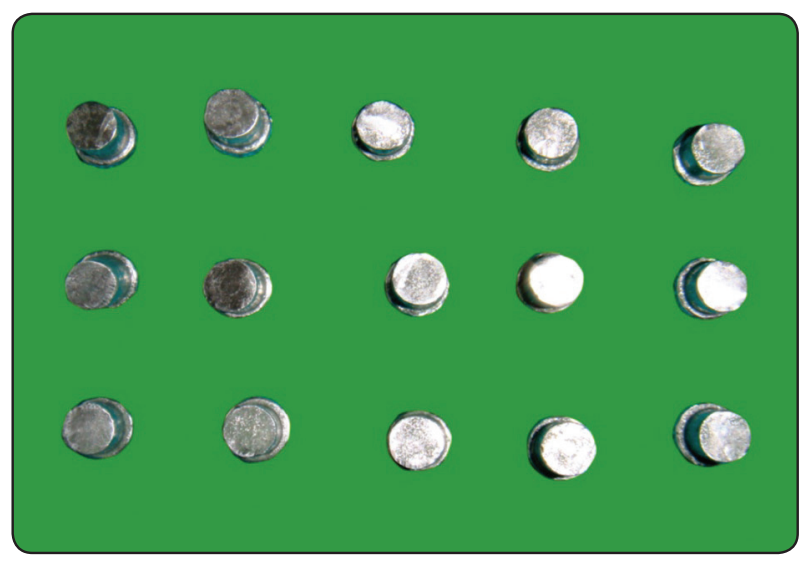

Fig. (3) Part of the metal samples prepared after cleaning and removal of debris.

\section{Application of the Opaque Layer}

All the samples were coated with a thin layer of base paste (Opaque and fire). Once the samples were cooled, they were coated with a layer of shade opaque and fired according to the manufacturer's instructions. The metal samples were considered acceptable for further porcelain build-up if the opaque layer completely masked the samples. The opaque layer thickness was standardized using a digital calliper.

\section{Customized jig for Ceramic Application}

To achieve a standardized layer of body porcelain (opaque, dentin, glaze, and Ivoclar Vivadent) of equal thickness on all the metal samples, a customized two-piece mold was fabricated. The middle portion in the mold had five cylindrical holes with a diameter $4 \mathrm{~mm}$ and length of $8 \mathrm{~mm}$ which allowed the porcelain build-up of $4 \mathrm{~mm}$ to metal samples of $4 \mathrm{~mm}$ length. Each metal specimen was placed within one of the five holes of a customized fabricated device which allowed the placement of porcelain to a height of $4 \mathrm{~mm}$ resulting in uniform metal porcelain sample dimensions.

To form the dentine porcelain the liquid was similarly added to the powder until a paste consistency was obtained, which was condensed in the holes of a device (fig.4). 


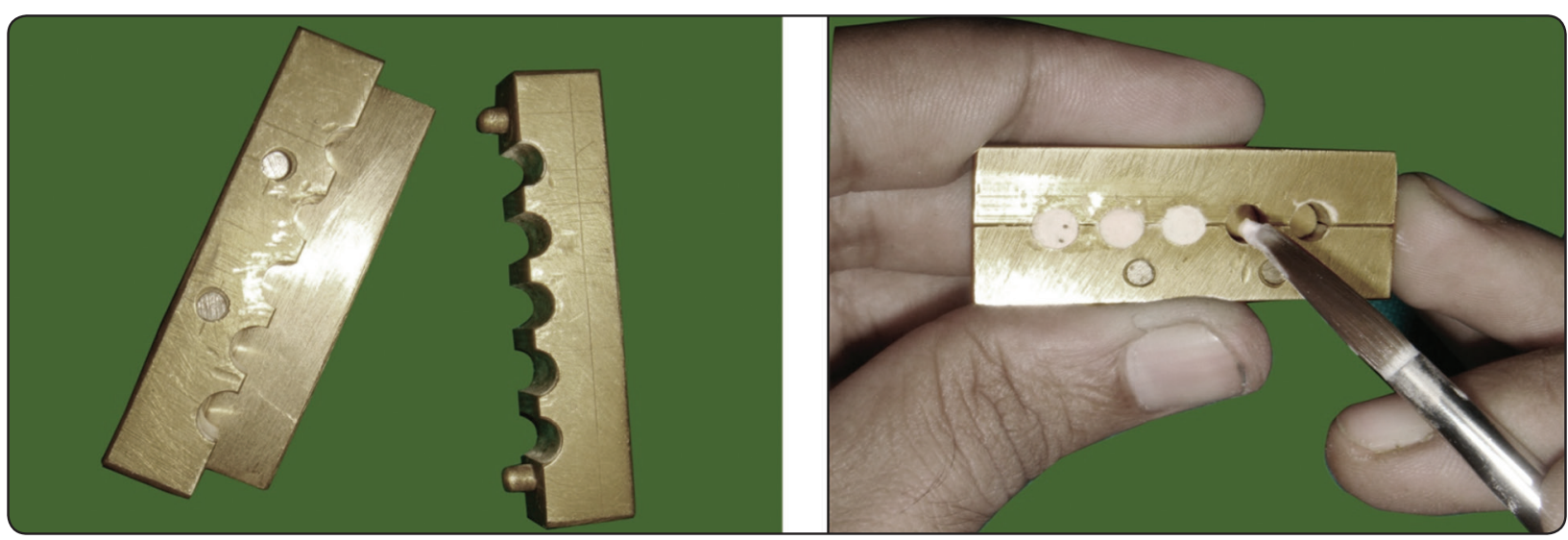

Fig. (4) Customized mold for porcelain build-up, left. Porcelain build-up with the help of mold.

After condensation was completed, the metal/ porcelain structure was carefully removed and fired.

The samples were then finished using sintered diamonds and subjected to polishing with silicon polishers to achieve a uniform thickness. The dimension of all the samples were checked using digital Vernier calliper. Samples were then cleaned with ultrasonic cleaner and steam cleaner.

These groups of samples were autoglazed according to the manufacturer's instructions. The samples were then ready for testing on universal testing machine (fig.5).

\section{Testing of the Samples}

To conduct the shear bond strength test, a custom fabricated brass apparatus formed by 2 independent pieces was used, (fig. 6). Piece A, initially cylindrical, was modified to generate a 0.4-cm-wide flat surface to allow the insertion of part B. The internal piece, B, had the same shape as the external piece $\mathrm{A}$, and worked like a piston during the mechanical test. On the flat surfaces of both $\mathrm{A}$ and $\mathrm{B}$, holes with a diameter of $4 \mathrm{~mm}$ were drilled so that the structure for part A had an upper displacement in relation to the hole of part $\mathrm{B}$. The matching of the holes allowed the introduction of the test specimen through both parts, at the same time. Thus, the ceramic portion of the specimen remained embedded within the piston (B), while the metal portion was embedded within the structure.

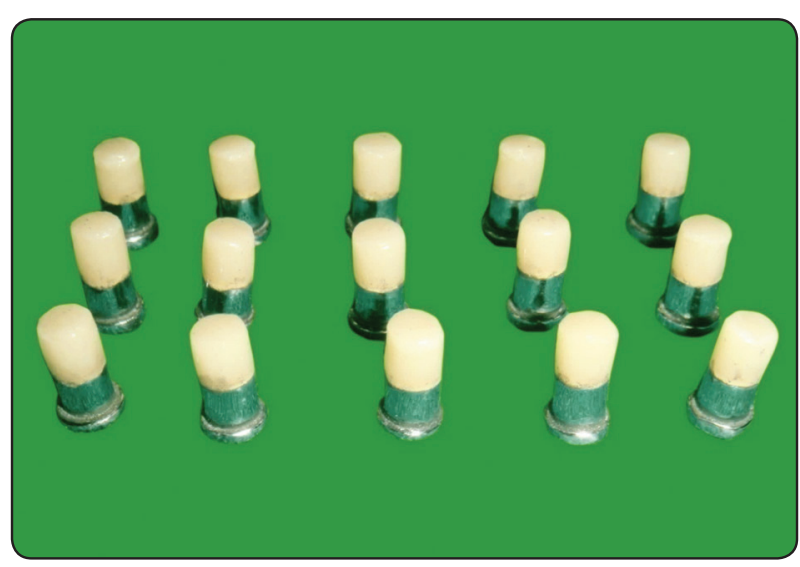

Fig. (5) Finished samples after cleaning and autoglazing.

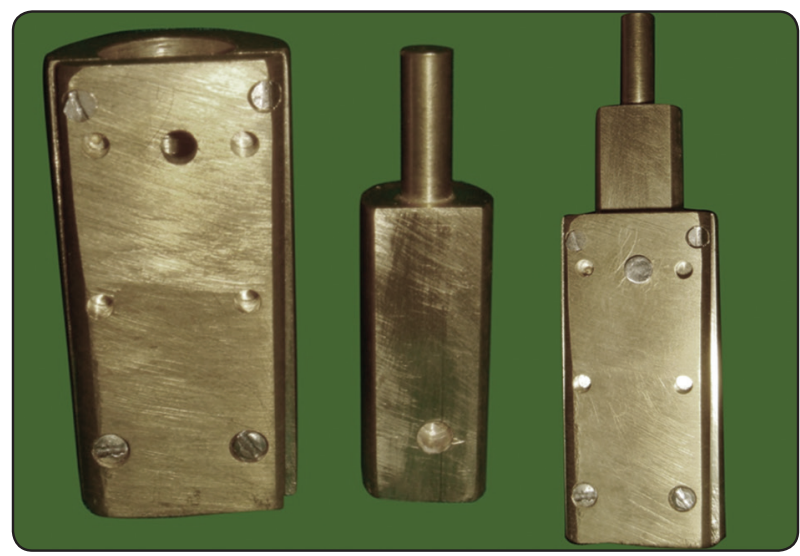

Fig. (6) Disassembled custom fabricated brass apparatus formed by 2 independent pieces, left. Same apparatus after assembling and adding the specimen. 
The shear bond strength tests were carried out at room temperature and performed in a universal testing machine (Instron 8874, MA, USA), with a load cell of $25 \mathrm{kN}$ capacity and under a crosshead speed of $0.5 \mathrm{~mm} / \mathrm{s}$ to apply a force to the upper cylindrical extension of part $B$, until fracture of the metal ceramic test specimen occurred with shear loading, (fig. 8).

All data of the shear bond strength as well as force to failure were collected, tabulated and statistically analysed by a statistical software package (SPSS 17.0; SPSS, Inc., Cary, NC, USA) where descriptive as well as one-way analysis of variance followed after testing the data normality by Shapiro-Wilk test. Finally, Tukey HSD (Honesty significant difference) comparison test was applied as post-hoc test.

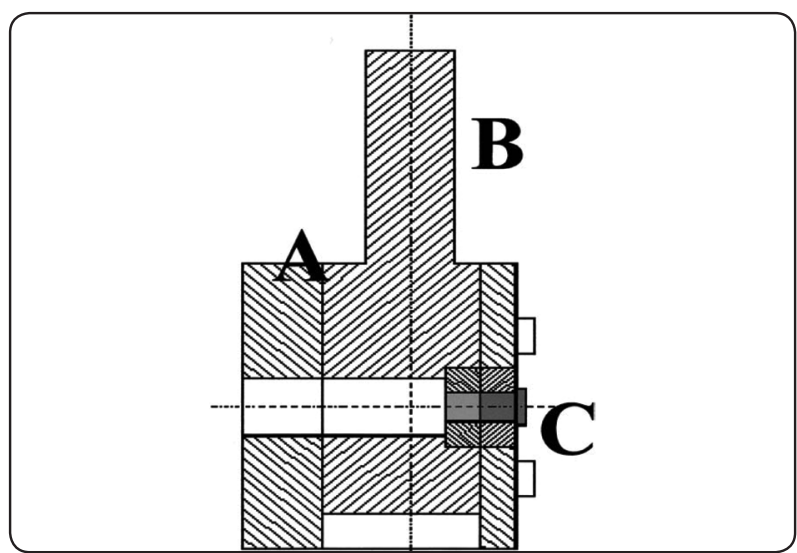

Fig. (7) diagram showing test apparatus: A, external portion; B, internal portion; $\mathrm{C}$, specimen

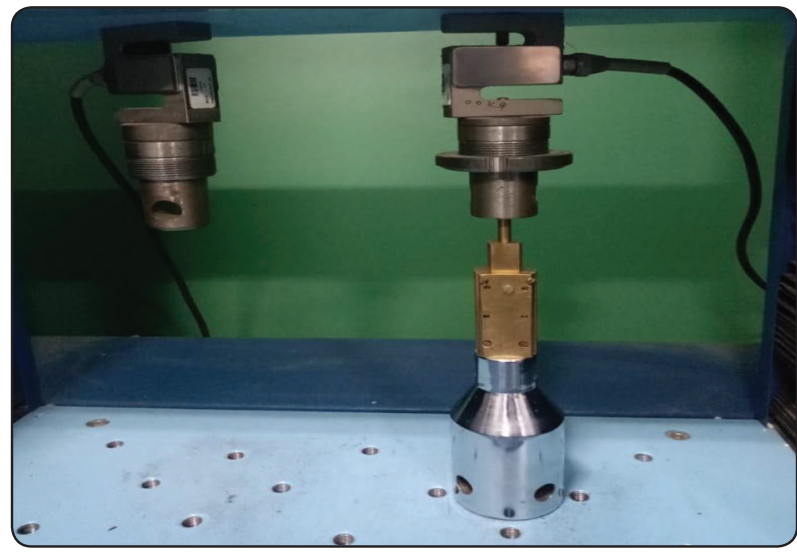

Fig. (8) Customized apparatus loaded by sample and attached to the universal testing machine before shear load application.

\section{RESULTS}

\section{Shear bond strength}

Samples data were statistically analysed to calculate descriptive values after checking the normality of data by Shapiro-Wilk test. The values of the means and standard deviations of the studied groups could be seen in table 1 and figure 9 .

Group B (positive control 100\% new alloy) showed the highest mean for shear bond strength of $41.45 \mathrm{Mpa}$ with a standard deviation of \pm 12.55 followed by group C (25\% once recasted alloy) with mean value $36.96 \mathrm{Mpa}$ and standard deviation \pm 10.11 . Group A (negative control $100 \%$ new

TABLE (1) Descriptive statistical analysis of shear bond strength (MPa) of the studied groups.

\begin{tabular}{|l|r|r|r|r|r|r|r|r|}
\hline \multirow{2}{*}{ Group } & \multirow{2}{*}{$\mathrm{N}$} & Mean & Std. Deviation & Std. Error & \multicolumn{2}{|c|}{ 95\% Confidence Interval for Mean } & \multirow{2}{*}{ Minimum } & \multirow{2}{*}{ Maximum } \\
\cline { 7 - 8 } & & & & & Lower Bound & Upper Bound & \\
\hline A & 15 & 31.37 & 9.82 & 2.54 & 25.93 & 36.81 & 20.37 & 52.43 \\
\hline B & 15 & 41.45 & 12.55 & 3.24 & 34.50 & 48.40 & 25.51 & 70.94 \\
\hline C & 15 & 36.97 & 10.11 & 2.61 & 31.37 & 42.56 & 16.46 & 55.34 \\
\hline D & 15 & 30.53 & 10.18 & 2.72 & 24.66 & 36.41 & 19.67 & 51.73 \\
\hline E & 15 & 27.89 & 6.72 & 1.73 & 24.17 & 31.61 & 18.85 & 41.79 \\
\hline F & 15 & 27.20 & 7.60 & 1.96 & 22.99 & 31.41 & 10.69 & 41.55 \\
\hline
\end{tabular}




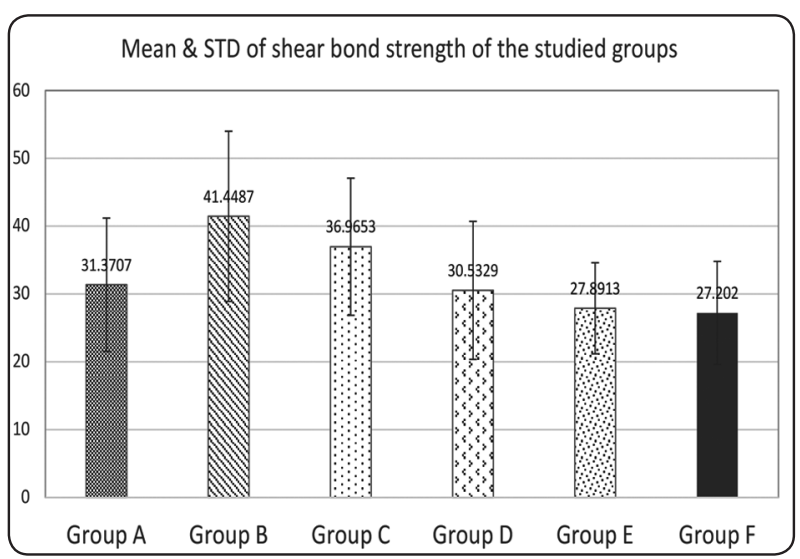

Fig. (9) Representative of the mean and standard deviations (STD) of the shear bond strength (MPa) of the studied groups. alloy) showed less value of shear bond strength $31.3 \pm 9.8 \mathrm{Mpa}$ followed by Group D (50\% once recasted alloy) with mean shear bond strength $(30.53 \pm 10.17 \mathrm{Mpa})$. Group E $(25 \%$ twice recasted alloy) shear bond strength was $(27.89 \pm 6.71 \mathrm{Mpa})$ and then finally group $\mathrm{F}(50 \%$ twice recasted alloy) showed the least mean shear bond strength (27.20 $\pm 7.60 \mathrm{Mpa})$.

Statistical analysis of variance (ANOVA test) was used to compare of the mean scores for the shear bond strength of the control groups with other groups by application. The calculated value of 6.137 at a probability level of 0.00 revealed that difference between the groups was significant.

TABLE (2) Multiple comparison between studied groups using Tukey HSD test as a post-hoc analysis

\begin{tabular}{|c|c|c|c|c|c|c|}
\hline \multirow[t]{2}{*}{ (I) Groups } & \multirow[t]{2}{*}{ (J) Groups } & \multirow{2}{*}{$\begin{array}{c}\text { Mean } \\
\text { Difference (I-J) }\end{array}$} & \multirow[t]{2}{*}{ Std. Error } & \multirow[t]{2}{*}{ Sig. } & \multicolumn{2}{|c|}{$95 \%$ Confidence Interval } \\
\hline & & & & & Lower Bound & Upper Bound \\
\hline \multirow{5}{*}{ Group A } & Group B & -10.07800 & 3.53 & 0.06 & -20.39 & 0.23 \\
\hline & Group C & -5.59467 & 3.53 & 0.61 & -15.91 & 4.72 \\
\hline & Group D & .83781 & 3.60 & 1.00 & -9.66 & 11.33 \\
\hline & Group E & 3.47933 & 3.53 & 0.92 & -6.83 & 13.79 \\
\hline & Group F & 4.16867 & 3.53 & 0.85 & -6.14 & 14.48 \\
\hline \multirow{5}{*}{ Group B } & Group C & 4.48333 & 3.53 & 0.80 & -5.83 & 14.79 \\
\hline & Group D & $10.91581 *$ & 3.60 & $.037 *$ & 0.42 & 21.41 \\
\hline & Group E & $13.55733^{*}$ & 3.53 & $.003 *$ & 3.25 & 23.87 \\
\hline & Group F & $14.24667 *$ & 3.53 & $.002 *$ & 3.94 & 24.56 \\
\hline & Group A & 10.07800 & 3.53 & 0.059 & -0.23 & 20.39 \\
\hline \multirow{5}{*}{ Group C } & Group B & -4.48333 & 3.53 & 0.801 & -14.79 & 5.83 \\
\hline & Group D & 6.43248 & 3.60 & 0.479 & -4.06 & 16.93 \\
\hline & Group E & 9.07400 & 3.53 & 0.117 & -1.24 & 19.38 \\
\hline & Group F & 9.76333 & 3.53 & 0.074 & -0.55 & 20.07 \\
\hline & Group A & 5.59467 & 3.53 & 0.612 & -4.72 & 15.91 \\
\hline \multirow{5}{*}{ Group D } & Group B & $-10.91581^{*}$ & 3.60 & $.037 *$ & -21.41 & -0.42 \\
\hline & Group C & -6.43248 & 3.60 & 0.479 & -16.93 & 4.06 \\
\hline & Group E & 2.64152 & 3.60 & 0.977 & -7.85 & 13.13 \\
\hline & Group F & 3.33086 & 3.60 & 0.939 & -7.16 & 13.82 \\
\hline & Group A & -.83781 & 3.60 & 1 & -11.33 & 9.66 \\
\hline \multirow{5}{*}{ Group E } & Group B & $-13.55733^{*}$ & 3.53 & $.003 *$ & -23.87 & -3.25 \\
\hline & Group C & -9.07400 & 3.53 & 0.117 & -19.38 & 1.24 \\
\hline & Group D & -2.64152 & 3.60 & 0.977 & -13.13 & 7.85 \\
\hline & Group F & .68933 & 3.53 & 1 & -9.62 & 11.00 \\
\hline & Group A & -3.47933 & 3.53 & 0.922 & -13.79 & 6.83 \\
\hline \multirow{5}{*}{ Group F } & Group B & $-14.24667 *$ & 3.53 & $.002 *$ & -24.56 & -3.94 \\
\hline & Group C & -9.76333 & 3.53 & 0.074 & -20.07 & 0.55 \\
\hline & Group D & -3.33086 & 3.60 & 0.939 & -13.82 & 7.16 \\
\hline & Group E & -.68933 & 3.53 & 1 & -11.00 & 9.62 \\
\hline & Group A & -4.16867 & 3.53 & 0.845 & -14.48 & 6.14 \\
\hline
\end{tabular}

* The mean difference is significant at the 0.05 level. 
A post-hoc analysis was done using Tukey HSD test to calculate the multiple comparisons between different groups, as shown in table 2 .

The results of the post-hoc comparison showed a significant difference at 0.05 level between group $\mathrm{B}$ (positive control group) and group D, E and F with significance values $(0.037,0.003$ and 0.002$)$ respectively. Non-significant values were calculated between group A (negative control group) and groups $\mathrm{B}, \mathrm{C}, \mathrm{D}, \mathrm{E}$ and $\mathrm{F}$ with significance values $(0.059,0.612,1.000,0.922$ and 0.845$)$. Similarly, the difference between groups C, D, E and F showed non-significant values $(0.479,0.117$ and 0.074$)$.

\section{DISCUSSION}

Based on the results of the current study, the null hypothesis could be partially accepted as laser treatment did in fact enhance the shear bond strength in samples with 50\% (once and twice) recasted alloys, as well as those with $25 \%$ twice recasted alloys.

Generally speaking, the strongest bond was achieved with the laser treated $100 \%$ fresh alloy (Group B). Although it was obviously greater than the non-laser treated $100 \%$ fresh alloy group (A), yet still statistically, there was no significant difference between the two groups. Such finding suggests that laser treatment is not significantly beneficial when the alloy used is $100 \%$ fresh. This could also be true when only $75 \%$ of fresh alloys are used since the bond strength values of this group (Group C) were statistically comparable to the $100 \%$ fresh groups, whether laser or non-laser treated. Significant difference between the $100 \%$ fresh laser treated samples and samples with recycled alloys started to be evident when the percentage of the once recasted alloy increased to $50 \%$ and when $25 \%$ to $50 \%$ of twice recasted alloy was used. However, the bond strength values of these samples were statistically comparable to the non-laser treated $100 \%$ fresh samples. These results emphasize the substantial benefit of laser treatment when once and twice recasted alloys with such ratios are used.
It is worthy to mention that comparable bond strength values were observed among groups D, E and F. Such observation proposes that: first, the effect of laser surface treatment compensated for the undesirable effects of recycling alloys; and second, it outweighed the effect of recasting times. However it is noteworthy that such statement cannot be generalized as it is true only for the number of recasting and ratios used in this study. In view of that, laser surface treatment could be recommended to improve the bond strength of recycled alloys that are used in the fabrication of porcelain fused to metal restorations.

The results of the present study were in accordance with Deepak et al, ${ }^{(21)}$. They appreciated the use of laser etching surface treatment with base metal alloys (Co-Cr and $\mathrm{Ni}-\mathrm{Cr}$ ). Their results showed higher values $(50.04 \pm 4.27 \mathrm{MPa})$ for laser etched samples which was approximately double the shear bond strength values of sandblasting surface treatment $(24.54 \pm 4.78 \mathrm{MPa})$. In contrast the results of the current study were not in agreement with Moslehifard et al, ${ }^{(25)}$ study. They concluded that $\mathrm{Nd}$ :YAG laser irradiation increased the shear bond strength of base metal alloy to porcelain (27.18 \pm 2.64 Mpa) but less than that gained by sandblasting method $(44.2 \pm 13.98 \mathrm{Mpa})$. Consequently, the difference could be claimed to variations in laser etching parameters used in their study if compared with the present study. They also mentioned in their study that they encourage further study of the laser parameters to get the maximum benefits.

Bonding porcelain to metal is dependent on some mechanisms (micro-mechanical retention, compressive adaption, chemical bonding and Van der Waals forces) ${ }^{(7)}$. The findings of the present study might be attributed to the micromechanical retention mechanism created by laser treatment which seems to be able to overcome the shortcomings of involving recasted alloy. Moreover, laser beam generates a superior characterization with proper depth on the alloy surface and form a good environment for porcelain adhesion on the 
alloys surface. In addition, the least average value of the shear bond strength of the present study (27.2 MPa) exceeded the limit of the bond strength as recommended by ISO standards which was $25 \mathrm{MPa}^{(25,26)}$. Accordingly, it has a valid clinical implication for porcelain fused to metal restorations.

The current study limitations could be summarized as the need for more combinations between different ratios and number of recasting with the use of different laser protocols as well as different alloys and different surface treatment combinations. The use of various assessment tools, microscopic surface studies and measurement techniques are also encouraged. However, these limitations keep space for further studies recommended to reveal the best tools and parameters to enhance bond strength.

\section{CONCLUSION}

Within the limitations of the present study, it could be concluded that laser surface treatment significantly enhanced the shear bond strength between Co-Cr alloys and porcelain materials, when the metal comprised $50 \%$ of once recasted alloy or $25 \%$ and $50 \%$ of twice recasted alloys, to the extent that it was comparable to $100 \%$ freshly used alloys.

\section{REFERENCES}

1. Gouveia PF, Schabbach LM, Souza JCM, et al.: New perspectives for recycling dental zirconia waste resulting from $\mathrm{CAD} / \mathrm{CAM}$ manufacturing process. Journal of cleaner production 152:454-63, 2017

2. Horasawa N, Marek M: The effect of recasting on corrosion of a silver-palladium alloy. Dental Materials 20:352-7, 2004

3. Vaillant-Corroy A-S, Corne P, De March P, et al.: Influence of recasting on the quality of dental alloys: A systematic review. The Journal of prosthetic dentistry 114:205-11, 2015

4. Bauer J, Cella S, Pinto MM, et al.: The use of recycled metal in dentistry: Evaluation of mechanical properties of titanium waste recasting. Resources, Conservation and Recycling 54:1312-6, 2010
5. Peraire M, Martinez-Gomis J, Anglada JM, et al.: Effects of recasting on the chemical composition, microstructure, microhardness, and ion release of 3 dental casting alloys and titanium. International Journal of Prosthodontics 20, 2007

6. Palaskar J, Nadgir DV, Shah I: Effect of recasting of nickelchromium alloy on its porosity. Contemporary clinical dentistry 1:237, 2010

7. Anusavice KJ, Shen C, Rawls HR: Phillips' science of dental materials: Elsevier Health Sciences, 2013

8. Madani AS, Rokni SR, Mohammadi A, et al:: The Effect of Recasting on Bond Strength between Porcelain and BaseMetal Alloys. Journal of Prosthodontics: Implant, Esthetic and Reconstructive Dentistry 20:190-4, 2011

9. Madhav VNV, Padmanabhan TV, Subramnian R: Evaluation of flexural bond strength of porcelain to used nickelchromium alloy in various percentages. Indian Journal of Dental Research 23:11, 2012

10. Atluri KR, Vallabhaneni TT, Tadi DP, et al.: Comparative evaluation of metal-ceramic bond strengths of nickel chromium and cobalt chromium alloys on repeated castings: An in vitro study. Journal of international oral health: JIOH 6:99, 2014

11. Beer-Lech K, Pałka K, Skic A, et al.: Effect of Recasted Material Addition on the Quality of Metal-Ceramic Bond: A Macro-, Micro-, and Nanostudy. Advances in Materials Science and Engineering 2018, 2018

12. Liu R, Johnston WM, Holloway JA, et al.: The effect of metal recasting on porcelain-metal bonding: a force-tofailure study. The Journal of prosthetic dentistry 104:16572,2010

13. Walczak M, Beer K, Surowska B, et al.: The issue of using remelted CoCrMo alloys in dental prosthetics. Archives of Civil and Mechanical Engineering 12:171-7, 2012

14. Stefanović VB, Lazić ZR, Mirković NJ, et al.: EDX analyisis of metal-ceramic interfaces of recasted nickelchromium dental alloys. Hemijska Industrija 72:149, 2018

15. Yavuz T, Acar A, Akman S, et al.: Effect of surface treatment on elemental composition of recast $\mathrm{NiCr}$ alloy. Materials Sciences and Applications 3:163, 2012

16. Lin H, Zhang H, Li X, et al.: Treatment of multiple ceramic alloys before recasting. The Journal of prosthetic dentistry 110:29-40, 2013 
17. Imirzalioglu P, Alaaddinoglu E, Yilmaz Z, et al.: Influence of recasting different types of dental alloys on gingival fibroblast cytotoxicity. The Journal of prosthetic dentistry 107:24-33, 2012

18. Al-Hiyasat AS, Darmani H: The effects of recasting on the cytotoxicity of base metal alloys. The Journal of prosthetic dentistry 93:158-63, 2005

19. Walton JN, Gardner FM, Agar JR: A survey of crown and fixed partial denture failures: length of service and reasons for replacement. Journal of Prosthetic Dentistry 56:41621,1986

20. Mirković N, Draganjac M, Stamenković D, et al.: Effect of recasting on the thickness of metal-ceramic interface of nickel-chromium and cobalt-chromium alloys. Vojnosanitetski pregled 65:365-9, 2008

21. Deepak K, Ahila SC, Muthukumar B, et al.: Comparative evaluation of effect of laser on shear bond strength of ceramic bonded with two base metal alloys: an in-vitro study. Indian Journal of Dental Research 24:610, 2013
22. Henriques B, Gonçalves S, Soares D, et al.: Shear bond strength comparison between conventional porcelain fused to metal and new functionally graded dental restorations after thermal-mechanical cycling. journal of the mechanical behavior of biomedical materials 13:194-205, 2012

23. Fischer J, Zbären C, Stawarczyk B, et al.: The effect of thermal cycling on metal-ceramic bond strength. Journal of dentistry 37:549-53, 2009

24. García-Sanz V, Paredes-Gallardo V, Mendoza-Yero O, et al: The effects of lasers on bond strength to ceramic materials: A systematic review and meta-analysis. PloS one 13: e0190736, 2018

25. Moslehifard E, Khosronejad N, Fahimipour F: Comparison of the Effect of Nd: YAG Laser and Sandblasting on Shear Bond Strength of a Commercial Ni-Cr Alloy to Porcelain. Journal of Dental Materials and Techniques 5:114-9, 2016

26. Kim JT, Cho SA. The effects of laser etching on shear bond strength at the titanium ceramic interface. The Journal of prosthetic dentistry 2009;101(2):101-106. 